\title{
Evolutionary Divergence and Convergence in Shape and Size Within African Antelope Proximal Phalanges
}

\author{
Julien Louys • Shaena Montanari - Thomas Plummer • \\ Fritz Hertel • Laura C. Bishop
}

Published online: 27 July 2012

(C) Springer Science+Business Media, LLC 2012

\begin{abstract}
Morphological convergence amongst species inhabiting similar environments but having different evolutionary histories is a concept central to evolutionary biology. Cases of divergent evolution, where there is morphological divergence between closely related species exploiting different environments, are less well studied. Here we show divergent evolution in the morphology of the proximal phalanges of several closely related African antelope species inhabiting different environments. This morphological divergence was consistently observed in both a neutral morphospace and an externally ordinated morphospace. Divergence, but not convergence, was also observed when size and shape were considered independently. Finally,
\end{abstract}

Electronic supplementary material The online version of this article (doi:10.1007/s10914-012-9211-4) contains supplementary material, which is available to authorized users.

J. Louys $\cdot$ L. C. Bishop

Research Centre in Evolutionary Anthropology and

Palaeoecology, School of Natural Sciences and Psychology,

Liverpool John Moores University,

Liverpool, UK

\section{J. Louys $(\bowtie)$}

School of Earth Sciences, The University of Queensland,

St. Lucia, QLD, Australia

e-mail: j.louys@uq.edu.au

S. Montanari

Richard Gilder Graduate School,

American Museum of Natural History,

New York, NY, USA

T. Plummer

Department of Anthropology, Queens College,

CUNY and NYCEP,

Flushing, NY, USA

F. Hertel

Department of Biology, California State University,

Northridge, CA, USA convergent evolution of the morphology of the proximal phalanges was observed, but only in the externally ordinated morphospace. Size shows less correlation with phylogeny than does shape. Therefore, we suggest that divergence in size will occur more readily when a species encounters new environmental conditions than divergence in shape. These findings are compatible with observations of rapid dwarfing on islands (Foster's rule).

Keywords Ecomorphology · Phalanges · Convergent evolution · Divergent evolution

\section{Introduction}

Morphological convergence amongst species sharing a similar environment but different evolutionary histories is a well-reported phenomenon that has been observed in many lineages across time. It remains a key concept in evolutionary biology (e.g., Hertel 1994; Schluter 2000; Stayton 2005, 2006). However, an understanding of divergent evolution is critical for many theories examining the interaction between the environment and the evolution of phenotype. Adaptive radiation, for example, relies on the divergence of many species from a common ancestor once new environments are encountered (Schluter 2000). Documentation and, more importantly, empirical tests for morphological divergence are critical for modern evolutionary theory and provide a useful comparator for modern studies of genetic divergence (Gatesy et al. 1997; Hassanin and Ropiquet 2004).

Antelopes (Mammalia: Bovidae) are found throughout the Old World but are most common in African environments where they show the highest level of continent-wide diversity. In Africa, they inhabit a range of habitats from open grasslands to dense forest to wetland. They are abundant in fossil assemblages and have long been used as paleoenvironmental indicators (Gentry 1970; Vrba 1980). 
Subsequently, postcranial elements commonly preserved in the fossil record have been the subject of ecomorphological analyses (Kappelman 1988, 1991; Plummer and Bishop 1994; Kappelman et al. 1997; DeGusta and Vrba 2003, 2005; Plummer et al. 2008; Bishop et al. 2011). These studies have revealed a correlation between habitat use and morphology of the antelope postcranial skeleton, as successful locomotor adaptation is intimately associated with organismal success (Plummer et al. 2008). Morphology will also be a consequence of the mechanical interaction between the postcranial skeleton and the substrate encountered (Scott 1985; Hamrick 2001; DeGusta and Vrba 2003). The morphology of the phalanges, in particular, should reflect these interactions as these elements are often in direct contact with the substrate being moved across (cursorial locomotion) or through (aquatic, arboreal, scansorial, and fossorial locomotion) (Kent and Miller 1997). Previous morphological analyses of mammalian phalanges have focused more on the distal phalanges (e.g., Macleod and Rose 1993; Hamrick 2001) as these are the most extreme elements of the limb and the most likely to be in contact with external environmental stimuli. There is also a rich body of literature examining primate and human phalanges in the context of hominin evolution (Deane and Begun 2008; Rolian et al. 2009; Almécija et al. 2009, 2010, 2012; Griffin and Richmond 2010; Kivell et al. 2011; Nelson et al. 2011; Congdon 2012).

Recently, the use of ecomorphological analyses of antelopes for habitat reconstructions has been questioned (Klein et al. 2010) on the basis that size, rather than shape, explains most of the morphological variation in antelope metapodials and astragali. Therefore, these authors argue, any discriminant analysis attempting to reconstruct habitats on the basis of elements that have not been independently linked to habitat or foraging strategy will make classification errors among like-sized genera. Body size is probably the most fundamental ecological trait, correlating with all aspects of an animal's biology including life history, physiology, behavior, and evolution (Peters 1983; Schmidt-Nielson 1984; Damuth and MacFadden 1990), and understanding how body size changes in response to different environments has important implications for understanding macroevolutionary processes (Evans et al. 2012). In bovids, the physical structure of the environment, as well as diet, has been shown to correlate with size (Brashares et al. 2000; Bro-Jørgensen 2008). Closed habitats tend to favor smaller-bodied species because this trait facilitates movement through dense vegetation and allows for effective camouflage. Open habitats tend to favor larger-bodied species in part because of increased seasonality and the body-size restrictions related to a grazing lifestyle (Brashares et al. 2000; Bro-Jørgensen 2008). Although early ecomorphological analyses attempted to adjust morphological data for size, effectively trying to remove size from shape (e.g., Kappelman 1988), this approach has been subsequently questioned and abandoned because of the intimate relationship between size and ecology (DeGusta and Vrba 2005; Kovarovic and Andrews 2007; Plummer et al. 2008; Bishop et al. 2011).

In order for any ecomorphological analysis to be valid, it must be demonstrated that the organisms under study exhibit both convergent and divergent evolution in response to new environmental conditions, and changes in size as well as shape are important aspects to consider. Although morphological convergence (and divergence) is assumed and qualitatively validated by ecomorphological studies (starting with Gentry (1970)), this has never been tested quantitatively, and particularly within a phylogenetic context. Here, therefore, we test the following two hypotheses: 1) that two closely related species in different environments are more different morphologically than two closely related species in the same environment (divergence); and 2) that two distantly related species in the same environment are more similar morphologically than two distantly related species in different environments (convergence). This is the first study where the influence of phylogeny (as opposed to taxonomy) is examined explicitly for analyses seeking to reconstruct habitats on the basis of bovid ecomorphological discriminant models. We focus on proximal phalanges because the morphology of these elements should reflect both a species' ambulation and the substrate because of their articulation with both the metapodials, and hence the limb, and the more distal phalanges, and hence the substrate.

\section{Materials and Methods}

We examined 343 proximal phalanges from 36 antelope species from: the American Museum of Natural History, New York, NY (AMNH), the National Museum of Natural History, Washington, DC (NMNH), and The Natural History Museum, London, UK (NHML). Adult, wild-shot specimens were measured in preference to zoo specimens, when available (zoo specimens, $n=10$ ). Each species was assigned to one of four broadly defined habitat preference categories used in previous ecomorphic studies (Scott 1985; Kappelman 1988, 1991; Kappelman et al. 1997) and the ethological literature (Dorst and Dandelot 1986; Kingdon 1997). These categories partition the environmental continuum from habitats generally lacking trees and bush to those with a continuous tree canopy. The habitat preference categories are: open (grassland, arid country, ecotones bordering open country), light cover (light bush, tall grass), heavy cover (heavy bush, woodland, densely vegetated swamp), and forest (Table 1).

We measured proximal phalanges following the measurement scheme detailed by Bishop et al. (2011) (Fig. 1, Table 2). We calculated a species mean for each measurement, and their 
Table 1 Antelope species examined, common names, preferred habitats, and number of individuals examined (n)

\begin{tabular}{|c|c|c|c|c|c|}
\hline ID & Tribe & Species & Common name & Preferred Habitat & $\mathrm{n}$ \\
\hline 1 & Tragelaphini & Tragelaphus imberbis & Lesser Kudu & Heavy Cover & 5 \\
\hline 2 & Tragelaphini & Tragelaphus strepsiceros & Greater Kudu & Heavy Cover & 11 \\
\hline 3 & Tragelaphini & Tragelaphus scriptus & Bushbuck & Forest & 27 \\
\hline 4 & Tragelaphini & Tragelaphus euryceros & Bongo & Heavy Cover & 18 \\
\hline 5 & Tragelaphini & Tragelaphus spekii & Sitatunga & Heavy Cover & 28 \\
\hline 6 & Aepycerotini & Aepyceros melampus & Impala & Light Cover & 19 \\
\hline 7 & Neotragini & Madoqua kirkii & Kirk's Dik-dik & Heavy Cover & 14 \\
\hline 8 & Antilopini & Antidorcas marsupialis & Springbok & Open & 12 \\
\hline 9 & Neotragini & Ourebia ourebi & Oribi & Light Cover & 11 \\
\hline 10 & Antilopini & Gazella granti & Grant's Gazelle & Open & 13 \\
\hline 11 & Antilopini & Gazella thomsoni & Thomson's Gazelle & Open & 15 \\
\hline 12 & Reduncini & Redunca fulvorufula & Mountain Reedbuck & Light Cover & 5 \\
\hline 13 & Reduncini & Redunca arundinum & Southern Reedbuck & Light Cover & 2 \\
\hline 14 & Reduncini & Redunca redunca & Bohor Reedbuck & Light Cover & 6 \\
\hline 15 & Reduncini & Kobus megaceros & Nile Lechwe & Heavy Cover & 1 \\
\hline 16 & Reduncini & Kobus ellipsiprymnus & Waterbuck & Heavy Cover & 4 \\
\hline 17 & Reduncini & Kobus kob & Kob & Light Cover & 3 \\
\hline 18 & Cephalophini & Cephalophus monticola & Blue Duiker & Forest & 11 \\
\hline 19 & Cephalophini & Cephalophus leucogaster & White-bellied Duiker & Forest & 5 \\
\hline 20 & Cephalophini & Cephalophus niger & Black Duiker & Forest & 1 \\
\hline 21 & Cephalophini & Cephalophus weynsi & Weyne's Duiker & Forest & 4 \\
\hline 22 & Cephalophini & Cephalophus natalensis & Red Forest Duiker & Forest & 2 \\
\hline 23 & Cephalophini & Cephalophus nigrifrons & Black-fronted Duiker & Forest & 3 \\
\hline 24 & Cephalophini & Sylvicapra grimmia & Common Duiker & Light Cover & 9 \\
\hline 25 & Cephalophini & Cephalophus dorsalis & Bay Duiker & Forest & 4 \\
\hline 26 & Cephalophini & Cephalophus silvicultor & Yellow-backed Duiker & Forest & 8 \\
\hline 27 & Alcelaphini & Connochaetes gnou & Black Wildebeest & Open & 5 \\
\hline 28 & Alcelaphini & Connochaetes taurinus & Blue Wildebeest & Open & 3 \\
\hline 29 & Alcelaphini & Alcelaphus buselaphus & Hartebeest & Open & 23 \\
\hline 30 & Alcelaphini & Damaliscus lunatus & Tsessebe & Open & 16 \\
\hline 31 & Alcelaphini & Beatragus hunteri & Hirola & Open & 4 \\
\hline 32 & Alcelaphini & Damaliscus pygargus & Bontebok & Open & 13 \\
\hline 33 & Hippotragini & Addax nasomaculatus & Addax & Open & 4 \\
\hline 34 & Hippotragini & Oryx gazella & Gemsbok & Open & 12 \\
\hline 35 & Hippotragini & Hippotragus equinus & Roan Antelope & Open & 6 \\
\hline 36 & Hippotragini & Hippotragus niger & Sable Antelope & Open & 16 \\
\hline
\end{tabular}

$\log _{10}$ values were used in both Principal Component Analysis (PCA) and Discriminant Function Analysis (DFA). These values are listed in the online supplementary information. Both sex and forelimb and hind limb phalanx data were pooled in the analyses, as two-way NPMANOVAs showed no significant interactions between sexes and habitat groups $(p=0.137)$ or limb position and habitat groups $(p=0.8582)$.

To investigate the role of phylogeny in ecomorphological analyses, a phylogenetic tree was constructed from genetic data based on sequences of the mitochondrial gene cytochrome b from Genbank. Accession numbers are listed in the online supplementary information. The sequences were aligned using MUSCLE (Edgar 2004) under default parameters, resulting in a matrix of 55 taxa and 1144 characters. The character matrix was analyzed in a parsimony framework using TNT v. 1.1 (Goloboff et al. 2008) utilizing the New Technology Search, ratchet, and drift options (100 random addition sequences), with the pronghorn (Antilocapra americana) as the outgroup. The data were also run on TNT (maximum parsimony) and RaxML (maximum likelihood) frameworks; the resulting topologies were nearly identical, therefore the parsimony analysis was used with a strict consensus tree created from the most parsimonious trees. The patristic distance 

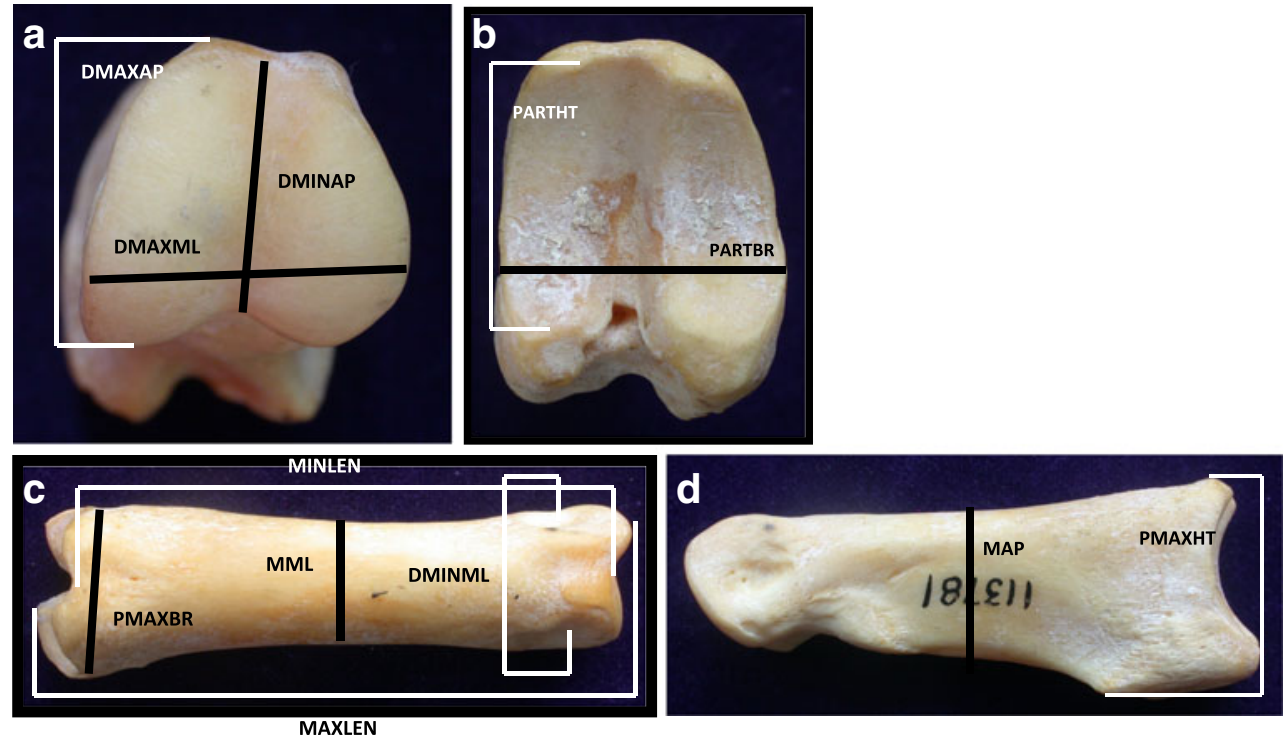

Fig. 1 Measurement scheme used on antelope proximal phalanges. Abbreviations as follows: MAXLEN maximum length; MINLEN minimum length; PMAXHT maximum height of proximal end; PARTHT proximal articular height; $P M A X B R$ maximum breadth of proximal end; $P A R T B R$ proximal articular breadth; $M A P$ midshaft

(the number of apomorphic step changes separating two taxa in the cladogram) between each species pair was calculated on the basis of this tree.

A neutral morphospace was constructed by subjecting the morphological variables to a Principal Component Analysis (PCA). This is a commonly employed algorithm in morphological studies aimed at extracting the most informative components of a multivariate dataset. A size-proxy variable was determined by comparing the first Principal Component (PC1) score of each species with its average species body mass (from Smith et al. 2004). We interpret PC2, which is independent of PC1, as a shape-proxy variable. Hereafter,

Table 2 List of measurements taken on the proximal phalanges and abbreviations used throughout the text

\begin{tabular}{ll}
\hline Abbreviation & Measurement \\
\hline MAXLEN & Maximum length \\
MINLEN & Minimum length \\
PMAXHT & Maximum height of proximal end \\
PARTHT & Proximal articular height \\
PMAXBR & Maximum breadth of proximal end \\
PARTBR & Proximal articular breadth \\
MAP & Midshaft anteroposterior diameter \\
MML & Midshaft mediolateral diameter \\
DMAXAP & Maximum anteroposterior dimension of the distal end \\
DMINAP & Minimum anteroposterior dimension of the distal end \\
DMAXML & Maximum mediolateral dimension of the distal end \\
DMINML & Minimum mediolateral dimension of the distal end \\
\hline
\end{tabular}

anteroposterior diameter; $M M L$ midshaft mediolateral diameter; $D M A X A P$ maximum anteroposterior dimension of the distal end; $D M I$ $N A P$ minimum anteroposterior dimension of the distal end; DMAXML maximum mediolateral dimension of the distal end; DMINML minimum mediolateral dimension of the distal end

we refer to these proxies as 'size' and 'shape,' respectively, cognizant that they are not a perfect representation of the true size or shape factors. We constructed a morphospace ordinated under the set of external conditions defined by habitat type using a Discriminant Function Analysis (DFA), with open, light cover, heavy cover, and forest as classifying variables. This type of analysis is commonly employed by paleoecologists attempting to reconstruct the likely habitat allocation of fossil skeletal elements (Plummer and Bishop 1994; Kovarovic et al. 2011). It maximizes the differences among species occurring in different habitat types and allows the assignment of unknown elements to a probable habitat type. On the basis of the two morphospaces, we were able to determine the morphological distance separating every species pair by calculating the Euclidean distance in the plot of the first two components for each space. This enabled us to construct two morphological distance matrices, one neutral (PCA) and the other ordinated externally (DFA).

Comparison between the patristic distance and the morphological distance matrices (PCA, DFA, size, and shape) was accomplished by Mantel tests using 9999 random permutations. Topology of the phylogenetic tree was mapped onto the two morphospaces using the methods described in O'Keefe (2002) and Stayton (2005). In this method each point representing a species in the morphospace corresponds to a terminal node on the phylogenetic tree. Centroids are calculated for each clade comprised of sister species or sister groups. Points are then plotted in the morphospace for each of these centroids, and branches connecting the nodes to the 
sister groups are drawn. These points correspond to internal nodes, and will always lie on the line connecting two groups or species, with the exception of an unresolved node in the cladogram, which is drawn as a polygon in the morphospace with the centroid and associated branch extending from its centre. This algorithm is then repeated successively for deeper nodes up to each basal node; however, in this study the basal node is not shown in order to maximize clarity of the resulting figure. This method in essence shows the phylogenetic relationships (represented by lines connecting closely related species or nodes) graphically in the morphospace. Two species or sister groups closely related but morphologically disparate are represented by a longer line, whereas two species or sister groups closely related and morphologically similar are represented by a shorter line. The middle node from each species or sister group pair in the resulting figure corresponds to an internal node of the cladogram, and represents the group centroid of these pairs in morphospace.

In this study, we define divergent evolution as the morphological divergence of two closely related species when these species exploit different environments. In a quantitative framework, this equates to a statistically significant difference in morphology between two closely related species inhabiting different environments relative to the difference in morphology between two closely related species inhabiting the same environment. We determined the cut off for closely related species by calculating the average patristic distance among all congeneric species and adding two standard deviations. Closely related species pairs were those whose patristic distance was less than this value, otherwise species were considered distantly related. Each species pair was then assigned to one of four categories: closely related same environment, closely related different environment, distantly related same environment, and distantly related different environment. Divergence and convergence were analysed by non-parametric Mann-Whitney U-tests.

\section{Results}

\section{Phylogenetic Results}

The strict consensus tree constructed from the six most parsimonious trees had 3247 steps (Fig. 2). This tree formed the basis from which the patristic distances were calculated. The topology of the phylogenetic tree mapped onto the morphospaces is shown in Fig. 3.

Functional Results

Summary statistics are listed in Tables 3-5. PC1 was strongly correlated with the log of average body mass $(r=0.9627$,

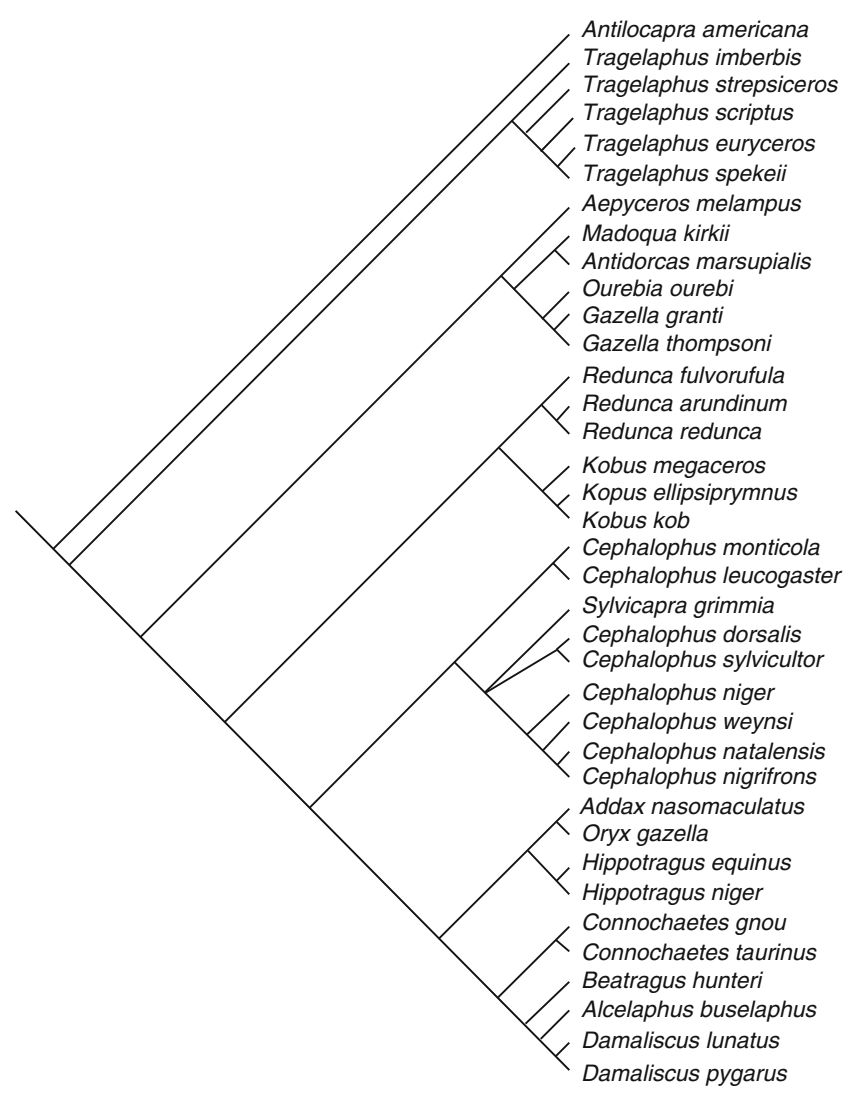

Fig. 2 Strict consensus tree of the 36 species of antelope examined

$p<0.001)$. Overall, forest-adapted antelopes were smaller than other species, as evinced by their lower PC1 values. Their lower PC2 values equate to relatively shorter phalanges (MAXLEN, MINLEN) combined with larger mediolateral dimensions at the distal end (DMAXML, DMINML) and wider midshaft mediolateral diameters (MML). Overall, this equates to squatter, broader phalanges at the distal end, where the proximal phalanges articulate with the middle phalanges. Heavy cover species also had generally lower PC2 values. However, they were generally larger in size. Light cover species were the second smallest (low PC1), but with high values of PC2, suggesting narrower phalanges at the distal end. Open adapted species all had high PC1 values, indicating large body sizes, but as a group they were not distinguishable along PC2.

Forest dwelling species were distinguished by low values of the first canonical variate associated with the DFA (DF1). This variate is positively affected by proximal articular breadth (PARTBR) and negatively by the maximum height (MAXHT). Hence, forest species are distinguished by taller, narrower proximal ends of the phalanges, where they articulate with the metapodials. Conversely, open adapted species were distinguished by high DF1 values, corresponding to shorter, wider proximal ends. Heavy cover species were distinguishable from other antelopes in having high DF2 values. 

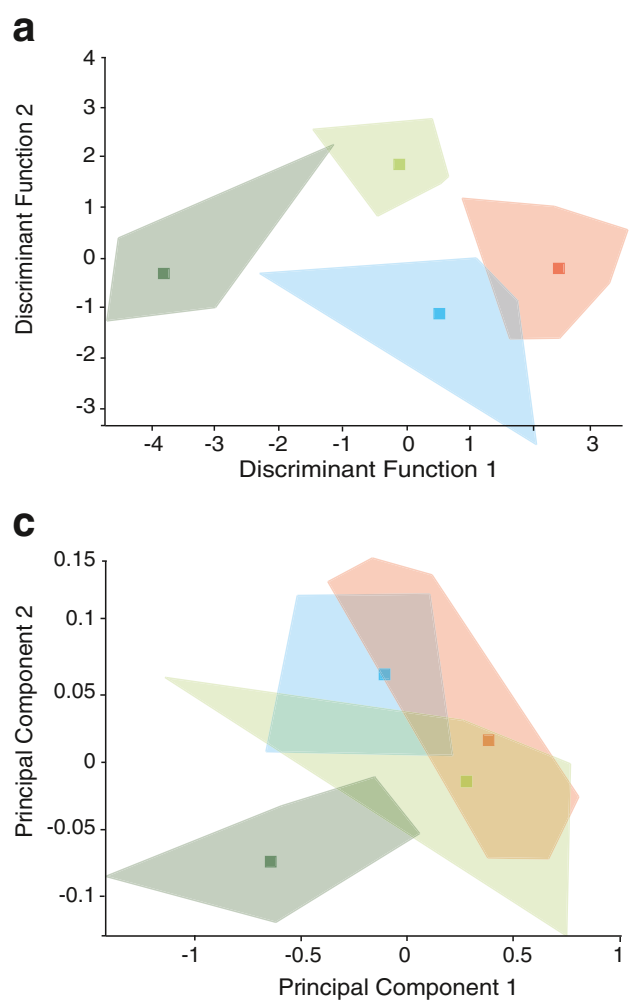

Fig. 3 Mapping the phylogenetic topology onto the different morphospaces examined. The ecologically weighted morphospace, $\mathbf{a}$ and $\mathbf{b}$ is represented by the first two components of a Discriminant Function Analysis using four habitat classification categories: forest (dark green), heavy cover (green), light cover (blue), and open (red). The unbiased morphospace, $\mathbf{c}$ and $\mathbf{d}$ is represented by the first two components of a Principal Component Analysis. For each of the habitat categories, squares represent the group centroid, outlines (shown in (a) and (c)) represent convex hulls. Phylogenetic relationships are shown only to tribal level with the exception of Aepycerotini and Neotragini, which is grouped with the Antilopini. Numbers refer to

This corresponds to a combination of narrower proximal articular breadth (PARTBR) and wider proximal breadth (PMAXBR). In other words, in these species the proximal end of the phalanx bulges out from the articular surface.

\section{Size and Shape}

In comparisons between morphological distances and phylogenetic distance, shape showed the highest correlation

\section{b}

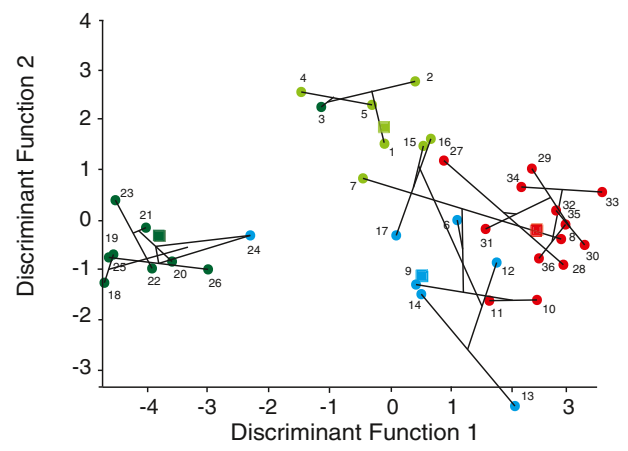

d

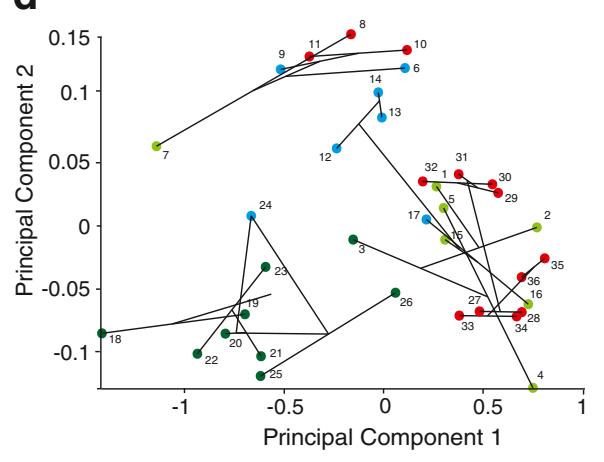

species as follows: 1 Tragelophus imberbis, 2 T. strepsiceros, 3 T. scriptus, 4 T. euryceros, 5 T. spekii, 6 Aepyceros melampus, 7 Madoqua kirkii, 8 Antidorcas marsupialis, 9 Ourebia ourebi, 10 Gazella granti, 11 G. thomsoni, 12 Redunca fulvorufula, $13 R$. arundinum, $14 R$. redunca, 15 Kobus megaceros, 16 K. ellipsiprymnus, 17 K. kob, 18 Cephalophus monticola, 19 C. leucogaster, 20 C. niger, 21 C. weynsi, 22 C. natalensis, 23 C. nigrifrons, 24 Sylvicapra grimmia, 25 C. dorsalis, 26 C. silvicultor, 27 Connochaetes gnou, 28 C. taurinus, 29 Alcelaphus buselaphus, 30 Damaliscus lunatus, 31 Beatragus hunter, 32 D. pygargus, 33 Addax nasomaculatus, 34 Oryx gazella, 35 Hippotragus equinus, 36 H. niger

$(\mathrm{r}=0.3096, p<0.0001)$ whereas size showed the lowest $(\mathrm{r}=$ $0.163, p=0.0067)$. Both the PCA and DFA morphospaces were significantly correlated with patristic distance (PCA: $\mathrm{r}=0.1641, p=0.0066$; DFA: $\mathrm{r}=0.3029, p<0.001$ ).

The topology of the phylogenetic tree mapped onto the morphospaces is shown in Fig. 3. Although the neutral morphospace (PCA) shows some degree of separation among habitat groups (Fig. 3c), the externally ordinated morphospace (DFA) shows the best separation among
Table 3 Summary statistics of Discriminant Function Analysis and Principal Component Analysis

\begin{tabular}{lllllll}
\hline & Eigenvalue & \% variance & Wilk's Lambda & Chi-square & df & Sig. \\
\hline PCA1 & 0.359806 & 97.432 & - & - & - & - \\
PCA2 & 0.00649092 & 1.7577 & - & - & - & - \\
DF1 & 6.421 & 79.9 & 0.042 & 88.605 & 30 & $<0.001$ \\
DF2 & 1.095 & 13.6 & 0.313 & 32.485 & 18 & 0.019 \\
\hline
\end{tabular}


Table 4 Component scores (PC) for each antelope species examined calculated in the Principal Component Analysis

\begin{tabular}{|c|c|c|}
\hline Species & $\mathrm{PC} 1$ & $\mathrm{PC} 2$ \\
\hline Tragelaphus imberbis & 0.26277 & 0.031737 \\
\hline Tragelaphus strepsiceros & 0.76717 & $1.74 \times 10^{-6}$ \\
\hline Tragelaphus scriptus & -0.15292 & -0.01062 \\
\hline Tragelaphus euryceros & 0.7454 & -0.12836 \\
\hline Tragelaphus spekii & 0.29868 & 0.014623 \\
\hline Aepyceros melampus & 0.10433 & 0.12632 \\
\hline Madoqua kirkii & -1.146 & 0.064116 \\
\hline Antidorcas marsupialis & -0.16588 & 0.1532 \\
\hline Ourebia ourebi & -0.51802 & 0.12577 \\
\hline Gazella granti & 0.11363 & 0.14063 \\
\hline Gazella thomsoni & -0.37145 & 0.1357 \\
\hline Redunca fulvorufula & -0.23848 & 0.062926 \\
\hline Redunca arundinum & -0.01285 & 0.087957 \\
\hline Redunca redunca & -0.02987 & 0.10742 \\
\hline Kobus megaceros & 0.305 & -0.01038 \\
\hline Kobus ellipsiprymnus & 0.72159 & -0.06221 \\
\hline Kobus kob & 0.20994 & 0.005699 \\
\hline Cephalophus monticola & -1.4122 & -0.08541 \\
\hline Cephalophus leucogaster & -0.69739 & -0.0697 \\
\hline Cephalophus niger & -0.79516 & -0.08504 \\
\hline Cephalophus weynsi & -0.61757 & -0.10281 \\
\hline Cephalophus natalensis & -0.93792 & -0.10096 \\
\hline Cephalophus nigrifrons & -0.59642 & -0.03192 \\
\hline Sylvicapra grimmia & -0.66779 & 0.008647 \\
\hline Cephalophus dorsalis & -0.61783 & -0.11892 \\
\hline Cephalophus silvicultor & 0.056969 & -0.05248 \\
\hline Connochaetes gnou & 0.47871 & -0.06691 \\
\hline Connochaetes taurinus & 0.68792 & -0.06878 \\
\hline Alcelaphus buselaphus & 0.57088 & 0.026385 \\
\hline Damaliscus lunatus & 0.54839 & 0.033348 \\
\hline Damaliscus hunteri & 0.37175 & 0.04186 \\
\hline Damaliscus dorcas & 0.1919 & 0.035858 \\
\hline Addax nasomaculatus & 0.37741 & -0.07116 \\
\hline Oryx gazella & 0.66554 & -0.07127 \\
\hline Hippotragus equinus & 0.805 & -0.025 \\
\hline Hippotragus niger & 0.69478 & -0.04026 \\
\hline
\end{tabular}

habitat categories (Fig. 3a). Morphological divergence is clearly visible on the DFA morphospace (Fig. 3b). In particular, the separation of the cephalophine Sylvicapra grimmia (24) away from the forest group centroid (the dominant habitat classification for the Cephalophini) towards the light cover group centroid, the reduncines Kobus megaceros (15) and $K$. ellipsiprymnus (16) away from the light cover group centroid (the dominant habitat classification for the Reduncini) to the heavy cover group centroid, and the neotragine Madoqua kirkii (7) away from the light cover and open group centroids (the dominant habitat classification of the Antilopinae) to the heavy cover group centroid. With the exception of $M$. kirkii, similar patterns can be seen in the neutral morphospace, but this is a result of differences in size (PC1) as well as shape (PC2) (Fig. 3d).

In the neutral morphospace (Fig. 4a), two closely related species inhabiting the same environment are more similar than two closely related species inhabiting different environments (divergence; $p<0.001$ ). Two distantly related species inhabiting the same environment are not more similar than

Table 5 Canonical scores (DF) for each antelope species examined calculated in the Discriminant Function Analysis

\begin{tabular}{lll}
\hline Species & DF1 & DF2 \\
\hline Tragelaphus imberbis & -0.111736331 & 1.53632483 \\
Tragelaphus strepsiceros & 0.401857205 & 2.783031448 \\
Tragelaphus scriptus & -1.137581335 & 2.29258763 \\
Tragelaphus euryceros & -1.453974396 & 2.561167179 \\
Tragelaphus spekii & -0.313062022 & 2.314558043 \\
Aepyceros melampus & 1.083497203 & 0.005758353 \\
Madoqua kirkii & -0.445372338 & 0.839242648 \\
Antidorcas marsupialis & 2.768485301 & -0.394452383 \\
Ouribia ourebi & 0.41063056 & -1.255179589 \\
Gazella granti & 2.381220916 & -1.569363689 \\
Gazella thomsoni & 1.622377304 & -1.604874941 \\
Redunca fulvorufula & 1.736887166 & -0.848111244 \\
Redunca arundinum & 2.037730562 & -3.738083719 \\
Redunca redunca & 0.503604188 & -1.464884844 \\
Kobus megaceros & 0.54075455 & 1.49640981 \\
Kobus ellipsiprymnus & 0.648430724 & 1.636134282 \\
Kobus kob & 0.087556896 & -0.296468594 \\
Cephalophus monticola & -4.693046641 & -1.268701309 \\
Cephalophus leucogaster & -4.561965982 & -0.705991924 \\
Cephalophus niger & -3.583573693 & -0.837535916 \\
Cephalophus weynsi & -3.9993855 & -0.125564024 \\
Cephalophus natalensis & -3.907700342 & -0.951842837 \\
Cephalophus nigrifrons & -4.519370378 & 0.390561507 \\
Sylvicapra grimmia & -2.310611383 & -0.29729561 \\
Cephalophus dorsalis & -4.617705788 & -0.731512887 \\
Cephalophus silvicultor & -3.006854285 & -0.980379811 \\
Connochaetes gnou & 0.879407681 & 1.203541667 \\
Connochaetes taurinus & 2.844528946 & -0.90742172 \\
Alcelaphus buselaphus & 2.314255165 & 1.037370915 \\
Damaliscus lunatus & 3.177217145 & -0.473643418 \\
Beatragus hunteri & 1.577723773 & -0.162720871 \\
Damaliscus dorcas & 2.702371713 & 0.18421258 \\
Addax nasomaculatus & 3.472015863 & 0.563202615 \\
Oryx gazella & 2.145551042 & 0.65853956 \\
Hippotragus equinus & 2.89607888 & -0.127785946 \\
\hline & 2.429757631 & -0.760827791 \\
\hline & & \\
Hippotragus niger & & \\
\hline
\end{tabular}


two distantly related species in different environments (convergence; $p=0.13$; Fig. $4 \mathrm{a}$ ). This pattern is equivalent to the test for size and shape (Fig. $4 \mathrm{~b}, \mathrm{~d} ; p<0.001$ and $p=$ 0.1391 ; and $p=0.003$ and $p=0.07$, respectively). In the externally ordinated ecospace (Fig. 4c), both convergence and divergence are observed (both $p<0.001$ ).

\section{Discussion}

Congruent with previous studies (Brashares et al. 2000; Bro-Jørgensen 2008), we found forest adapted species had smaller proximal phalanges than other antelopes. However, we found that the antelopes preferring heavy cover were of similar size to light cover species, at least in our sample. This trend cannot be explained completely by diet, as many of the Tragelaphini examined in this habitat category are browsers or mixed feeders (Gagnon and Chew 2000). Size varies not only as a result of diet but also other ecological traits such as competition and predation, and it is likely that these variables are also influencing this trend. Both forest and heavy cover species had relatively broad distal ends of the proximal phalanges. In horses, broader phalanges have been suggested to be an adaptation to soft substrates (van Aspen 2010), and this explanation might be possible for antelopes as well. More likely though, this shape would give greater support to phalanges that manoeuver in more cluttered habitats, and therefore experience greater loads from all directions compared to open habitat species.

Light cover species and most open habitat species had relatively narrower and longer distal ends, suggesting locomotion over harder/drier substrates in less structurally
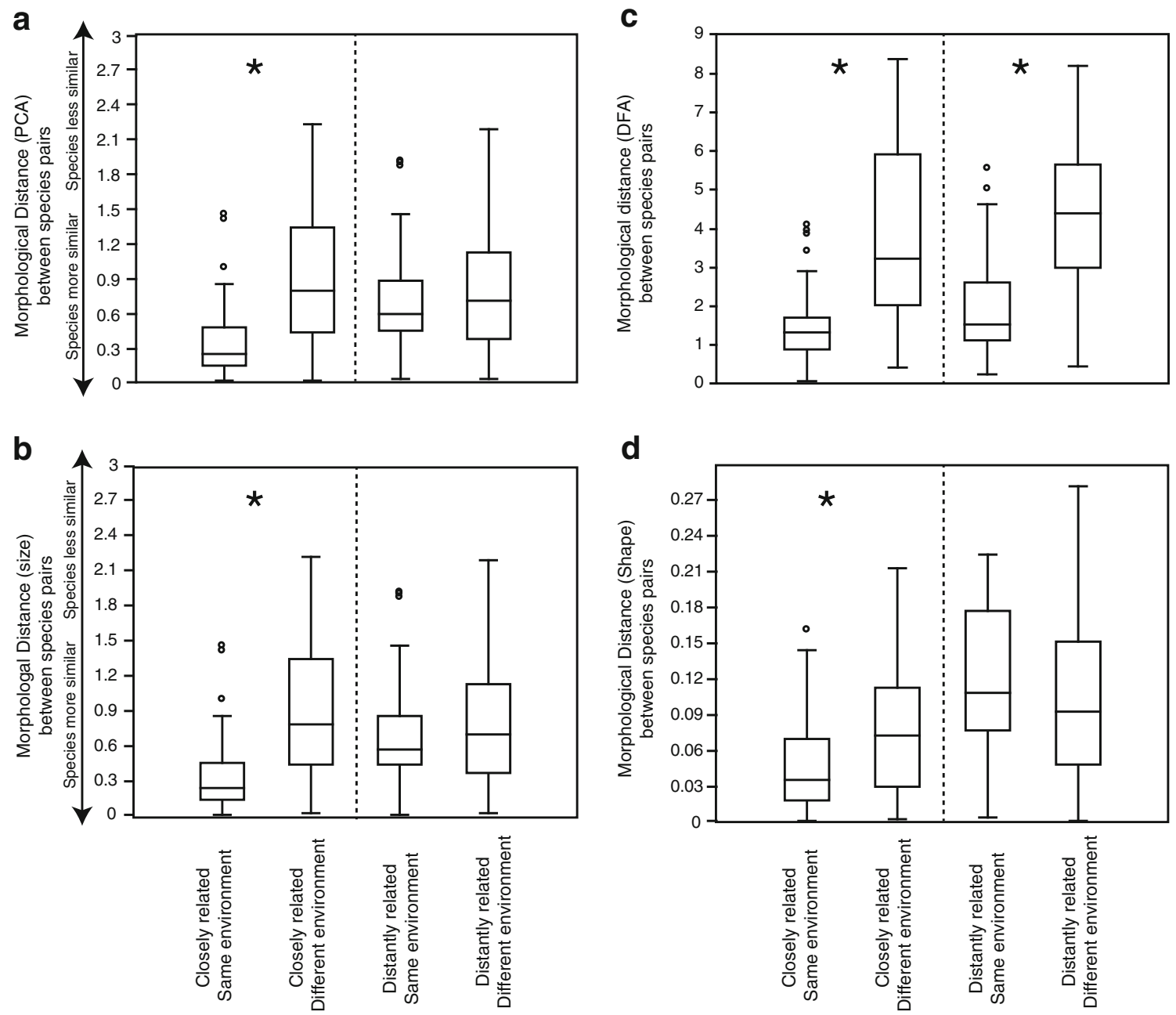

Fig. 4 Box plot of the Euclidean distances between each species pair for (a) neutral morphospace, (b) size space, (c) externally ordinated morphospace, and (d) shape space. Species classified according to level of relatedness based on average patristic distance between congeneric species, and environments represented by the habitat classification categories of forest, heavy cover, light cover, and open. For each

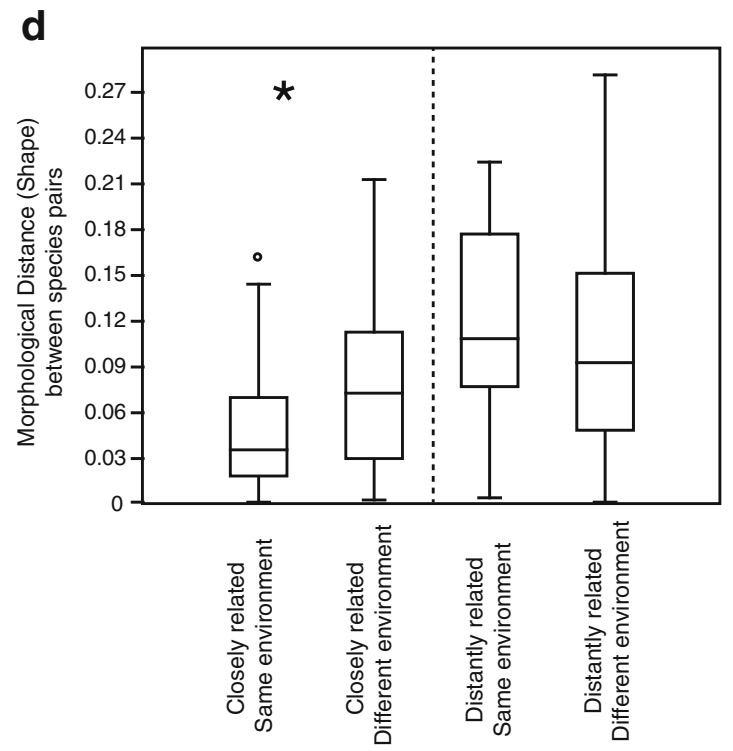

group, the 25-75 percent quartiles are drawn using the box, the median is shown with a horizontal bar in the box, the whiskers accompanying the box show minimum and maximum values, and outliers are shown as points. Asterisks indicate significant differences $(p \leq 0.05)$ between the groups 
complex habitats. Elongation of distal limb elements is also an adaptation for more cursorial species that typically inhabit more open habitats (Hildebrand and Goslow 2001; Pough et al. 2008). In mammals exhibiting an unguligrade posture, such as antelopes, the weight of the body is supported entirely by the distal phalanges, with the proximal and medial phalanges effectively contributing to the stridelength of the animal (Pough et al. 2008). Muscles in the distal part of the limb are reduced in favor of using tendons to transmit muscular forces in order to reduce the weight of this part of the limb (Hildebrand and Goslow 2001). This effectively reduces limb inertia, increasing speed and longdistance travel, but at the cost of decreased manoeuvrability. Therefore, we would expect antelopes found in more open habitats to have narrower, more gracile phalanges compared to more forest adapted species, as these species are more likely to rely on speed and endurance over open terrain for predator evasion than manoeuvrability through dense vegetation. Finally, open habitat species were larger on average (higher PC1 scores) than antelopes in the other habitat categories. This is possibly a consequence of diet as most are grazers, although increased size may also contribute to increased speed in open habitats. In contrast, small compact bodies appear to be adaptive in dense habitats for greater manoeuvrability (Bro-Jørgensen 2008).

Our results demonstrate morphological divergence between closely related antelope species inhabiting different environments, regardless of phylogeny (Fig. 4a, c). Divergence was observed in both size and shape (Fig. 4b, d), suggesting that any size-related changes occurring as a result of habitat differentiation would be accompanied by changes in shape. Convergent evolution, however, was only observed in the externally ordinated ecospace (DFA).

The mantel tests indicated that shape is more closely correlated with phylogeny than is size, which shows the lowest correlation. Our results suggest size may be more labile to a change in environmental conditions than shape as it is not as phylogentically constrained. If flexibility in size over shape is real, the first phenotypic changes observable once a species is exposed to different environmental conditions should be size related. This conclusion is borne out by observations of island dwarfing (Foster's rule [Foster 1964]), where changes in size have been observed as occurring as quickly as within 150 years (Yom-Tov et al. 1999).

Our results have important implications for paleoecologists. First, we show that convergence and divergence were observed in an externally ordinated morphospace, supporting ecomorphological analyses in this space. Therefore, if convergent and divergent evolution of a skeletal element under investigation can be demonstrated in this space, such as it has here, then this means this element satisfies the assumptions of ecomorphological analyses aimed at discriminating habitats. Although phylogeny plays a role in both the size and shape of any skeletal element, we show that size is less correlated with phylogeny than shape. However, neither of the neutral morphospaces (shape nor size) fulfilled the convergence/divergence assumptions of ecomorphological models, and hence may not be suitable for building discriminant models for habitat prediction. We also show that an externally ordinated morphospace may more accurately reflect the phylogenetic relationships of the species under examination, as well as their functional similarities, compared to a neutral morphospace.

Finally, our study provides a quantitative method for testing divergence amongst species within a phylogenetic context. Analyses and tests for divergence impact many fields of evolutionary biology and are just as important as those for convergence. Our results suggest that size may be relaxed more quickly than shape in the context of new environmental conditions. African antelopes are continental species, and it would be interesting to see if the pattern of divergence we describe is followed in island species, where the ecological pressures for a change in size are considered much greater (e.g., Sondaar 1991; Yom-Tov et al. 1999; Millien and Damuth 2004).

Acknowledgments We thank E. Westwig (AMNH), L. Gordon (NMNH), and the NHML for their curatorial assistance; JL and LCB acknowledge the support of The Leverhulme Trust (FC00754C); TP acknowledges support from the Professional Staff Congress-City University of New York Research Award Program; FH acknowledges the CSUN Office of Research and Sponsored Projects.

\section{References}

Almécija S, Alba DM, Moyà-Solà S (2009) Pierolapithecus and the functional morphology of Miocene ape hand phalanges: paleobiological and evolutionary implications. J Hum Evol 57: 284-297

Almécija S, Moyà-Solà S, Alba DM (2010) Early origin for humanlike precision grasping: a comparative study of pollical distal phalanges in fossil hominins. PLoS ONE 5(7): e11727 (doi:10.1371/journal.pone.0011727)

Almécija S, Alba DM, Moyà-Solà S (2012) The thumb of Miocene apes: new insights from Castell de Barberà (Catalonia, Spain). Am J Phys Anthropol. doi:10.1002/ajpa.22071

Bishop LC, Plummer TW, Hertel F, Kovarovic K (2011) Paleoenvironments of Laetoli, Tanzania as determined by antelope habitat preferences. In: Harrison T (ed) Paleontology and Geology of Laetoli: Human Evolution in Context. Springer, Dordrecht, pp 355-366

Brashares JS, Garland T, Arcese P (2000) Phylogenetic analysis of coadaptation in behavior, diet, and body size in the African antelope. Behav Ecol 11:452-463

Bro-Jørgensen J (2008) Dense habitat selecting for small body size: a comparative study on bovids. Oikos 117: 729-737

Congdon KA (2012) Interspecific and ontogenetic variation in proximal pedal phalangeal curvature of great apes (Gorilla gorilla, Pan troglodytes and Pongo pygmaeus) Int J Primatol 33:418-427

Damuth J, MacFadden BJ (1990) Body Size in Mammalian Paleobiology. Cambridge University Press, Cambridge

Deane AS, Begun DR (2008) Broken fingers: retesting locomotor hypotheses for fossil hominoids using fragmentary proximal 
phalanges and high-resolution polynomial curve fitting (HRPCF). J Hum Evol 55:691-701

DeGusta D, Vrba E (2003) A method for inferring paleohabitats from the functional morphology of bovid astragali. J Archaeol Sci 30:1009-1022

DeGusta D, Vrba E (2005) Methods for inferring paleohabitats from the functional morphology of bovid phalanges. J Archaeol Sci 32:1099-1113. doi:10.1016/j.jas.2005.02.010

Dorst J, Dandelot P (1986) A Field Guide to Larger Mammals of Africa. Collins, London

Edgar RC (2004) MUSCLE: multiple sequence alignment with high accuracy and high throughput. Nucleic Acids Res 32:1792-97. doi:10.1093/nar/gkh340

Evans AR, Jones D, Boyer AG, Brown JH, Costa DP, Morgan Ernest SK, Fitzgerald EMG, Fortelius M, Gittleman JL, Hamilton MJ, Harding LE, Lintulaakso K, Lyons SK, Okie JG, Saarinen JJ, Sibly RM, Smith FA, Stephens PR, Theodor JM, Uhen MD (2012) The maximum rate of mammal evolution. Proc Nat Acad Sci USA. doi:10.1073/pnas.1120774109

Foster JB (1964) Evolution of mammals on islands. Nature 202: 234 235. doi: $10.1038 / 202234 \mathrm{a} 0$

Gagnon M, Chew AE (2000) Dietary preferences in extant African bovidae. J Mammal 81:490-511

Gatesy J, Amato G, Vrba E, Schaller G, DeSalle R (1997) A cladistic analysis of mitochondrial ribosomal DNA from the Bovidae. Mol Phylogenet Evol 7:303-319. doi:10.1006/mpev.1997.0402

Gentry AW (1970) The Bovidae (Mammalia) of the Fort Ternan fossil fauna. In: Leakey LSB, Savage RJG (eds) Fossil Vertebrates of Africa, vol. 2. Academic Press, London, pp 243-323

Goloboff PA, Farris JS, Nixon KN (2008) TNT, a free program for phylogenetic analysis. Cladistics 24:774-786. doi:10.1111/ j.1096-0031.2008.00217.x

Griffin NL, Richmond BG (2010) Joint orientation and function in great ape and human proximal pedal phalanges. Am J Phys Anthropol 141:116-123

Hamrick MW (2001) Development and evolution of the mammalian limb: adaptive diversification of nails, hooves and claws. Evol Dev 3:355-363

Hassanin A, Ropiquet A (2004) Molecular phylogeny of the tribe Bovini (Bovidae, Bovinae) and the taxonomic status of the Kouprey, Bos sauveli Urbain 1937. Mol Phylogenet Evol 33:896-907

Hertel F (1994) Diversity in body size and feeding morphology within past and present vulture assemblages. Ecology 75:1074-1084. doi: $10.2307 / 1939431$

Hildebrand M, Goslow T (2001) Analysis of Vertebrate Structure, 5th edn. John Wiley and Sons, New York

Kappelman J (1988) Morphology and locomotor adaptations of the bovid femur in relation to habitat. J Morphol 198: 119-130. doi:10.1002/jmor.1051980111

Kappelman J (1991) The paleoenvironment of Kenyapithecus at Fort Ternan. J Hum Evol 20:95-129. doi:10.1016/0047-2484 (91)90053-X

Kappelman J, Plummer TW, Bishop LC, Duncan A, Appleton S (1997) Bovids as indicators of Plio-Pleistocene paleoenvironments of East Africa. J Hum Evol 32: 95-129. doi:10.1006/jhev.1996.0105

Kent GC, Miller L (1997) Comparative Anatomy of the Vertebrates, 8th edn. Wm. C. Brown Publishers, Dubuque, IA

Kingdon J (1997) The Kingdon Guide to African Mammals. Academic Press, San Diego

Kivell TL, Kibli JM, Churchill SE, Schmid P, Berger LR (2011) Australopithecus sediba hand demonstrates mosaic evolution of locomotor and manipulative abilities. Science 333:1411-1417

Klein RG, Fransiscus RG, Steele TE (2010) Morphometric identification of bovid metapodials to genus and implications for taxon-free habitat reconstruction. J Archaeol Sci 37:389-401. doi:10.1016/ j.jas.2009.10.001

Kovarovic KM, Andrews P (2007) Bovid postcranial ecomorphological survey of the Laetoli paleoenvironment. J Hum Evol 52:663-690

Kovarovic K, Aiello LC, Cardini A, Lockwood CA (2011) Discriminant functions analyses in archaeology: are classification rates too good to be true? J Archaeol Sci 38:3006-3018

Macleod N, Rose KD (1993) Inferring locomotor behavior in Paleogene mammals via eignenshape analysis. Am J Sci 293:300-355

Millien V, Damuth J (2004) Climate change and size evolution in an island rodent species: new perspectives on the island rule. Evolution 58:1353-1360. doi:10.1111/j.0014-3820.2004.tb01713.x

Nelson E, Rolian C, Cashmore L, Shultz S (2011) Digit ratios predict polygyny in early apes, Ardipithecus, Neanderthals and early modern humans but not in Australopithecus. Proc R Soc B 278:1556-1563.

O'Keefe FR (2002) The evolution of plesiosaur and pliosaur morphotypes in the Plesiosauria (Reptilia: Sauropterygia). Paleobiology 28:101-112. doi:10.1666/0094-8373

Peters RH (1983) The Ecological Implications of Body Size. Cambridge University Press, Cambridge

Plummer TW, Bishop LC (1994) Hominid paleoecology at Olduvai Gorge, Tanzania as indicated by antelope remains. J Hum Evol 29:321-362. doi:10.1006/jhev.1994.1035

Plummer TW, Bishop LC, Hertel F (2008) Habitat preference of extant African bovids based on astragalus morphology: operationalizing ecomorphology for palaeoenvironmental reconstruction. J Archaeol Sci 35:3016-3027. doi:10.1016/j.jas.2008.06.015

Pough FH, Janis CM, Heiser JB (2008) Vertebrate Life, 8th edn. Benjamin Cummings, NY

Rolian C, Lieberman DE, Hamill J, Scott JW, Werbel W (2009) Walking, running and the evolution of short toes in humans. J Experim Biol 212:713-721

Schluter D (2000) The Ecology of Adaptive Radiation. Oxford University Press, Oxford

Schmidt-Nielson K (1984) Scaling: Why is Animal Size so Important? Cambridge University Press, Cambridge

Scott KM (1985) Allometric trends and locomotor adaptations in the Bovidae. Bull Am Mus Nat Hist 197:197-288

Smith FA, Brown JH, Haskell JP, Lyons SK, Alroy J, Charnov EL, Dayan T, Enquist BJ, Ernest SKM, Hadly EA, Jones KE, Kaufman DM, Marquet PA, Maurer BA, Niklas KJ, Porter WP, Tiffney B, Willig MR (2004) Similarity of mammalian body size across the taxonomic hierarchy and across space and time. Am Nat 163:672-691. doi:10.1086/382898

Sondaar PY (1991) Island mammals of the past. Sci Progr 75: 249-264

Stayton CT (2005) Morphological evolution of the lizard skull: a geometric morphometrics survey. J Morphol 263:47-59. doi:10.1002/jmor.10288

Stayton CT (2006) Testing hypotheses of convergence with multivariate data: morphological and functional convergence among herbivorous lizards. Evolution 60:824-841. doi:10.1111/j.00143820.2006.tb01160.x

van Aspen EN (2010) Ecomorphological adaptations to climate and substrate in late middle Pleistocene caballoid horses. Palaeogeogr Palaeoclimat Palaeoecol 297:584-596

Vrba ES (1980) The significance of bovid remains as indicators of environment and predation patterns. In: Beherensmeyer AK, Hill AP (eds) Fossils in the Making: Vertebrate Taphonomy and Paleoecology. University of Chicago Press, Chicago, pp 247-271

Yom-Tov Y, Yom-Tov S, Moller H (1999) Competition, coexistence, and adaptation amongst rodent invaders to Pacific and New Zealand islands. J Biogeogr 26: 947-958. doi:10.1046/j.13652699.1999.00338.x 